\title{
A systematic approach to improve health equity within 3rd world communities -evidence from the comparison of Haiti and China
}

\author{
Roodelin Jean ${ }^{1}$, Aidogie Osamuyimen ${ }^{2}$ \\ ${ }^{I}$ (Medicine \& Health Management, Tongji Medical College/Huazhong University of Science \& Technology, \\ People's Republic of China) \\ ${ }^{2}$ (Medicine \& Health Management, Tongji Medical College/Huazhong University of Science \& Technology, \\ People's Republic of China)
}

\begin{abstract}
This paper is a comparative study of the healthcare sector in Haiti and China. The primary objective was to find a systematic approach aimed at ensuring equitable distribution of healthcare services in third world countries, particularly in least developed countries using Haiti an economically impoverished country in the Western Hemisphere as the litmus test. To establish the proposed hypothesis, the study relied on existing research through an extensive literature review that focused on a comparative analysis of an almost non-existing healthcare system in Haiti to that of China's improved and evolving healthcare system. Whilst China is regarded internationally as a developing country despite its remarkable economic achievements within the past three to four decades, Haiti also a developing country could be regarded as under-developed compared to China. By conducting an investigation into selected areas within the health sectors in both countries, this paper hypothesized that China's success and feasible improvement within the health sector could be used as template for improvement in the healthcare sector in Haiti and as lessons for other third world countries to emulate. This explanatory study relied on data from organizations including the Global Health Data Exchange, the Institute for Health Metrics Evaluation, the Demographic and Health Survey Program to make quantitative analysis using analytical tools including the Health Equity Assessment Toolkit (HEAT) from the World Health Organization and the Health Equity Monitor (HEM) with data from the Global Health Observatory. The combination of these tools enabled the study to make proper assessment, analyze data, and tackle the research problem, questions and interpretation of reviewed literature. The results from the comparisons made revealed that strict adherence and continuous improvement of policies in under-developed countries despite financial restraints has high probable impacts other than non-adherence.
\end{abstract}

Keywords: Healthcare, Systematic approach, Haiti, China

\section{INTRODUCTION}

In order to provide an equitable healthcare system in which all citizens feel well catered for and respected, it is important to have "a clear understanding of people's perceptions of equitable healthcare services within their cultural or social context. Puentes-Markides (1992) supports this claim, when she argued that health policy proposals and health care systems need to recognize the perspectives and needs of the most disadvantaged populations.

Despite these admonitions, traditional solutions to the problems of inequitable healthcare are nearly always informed more by the perspective of the health policy makers than by the less advantaged populations that are the target of the intervention (Felker-Kantor, 2011). Results following this notion have often produced health care systems built on insensitive top down policies, which have increased disparities in health care particularly among racial and ethnic minority (Puentes-Markides 1992).

Since the 1791 slave revolution in Haiti, Haitians have endured continuous western interventions and occupations, internal governmental corruption, and violent episodes. For decades, the Caribbean nation has been subject to international aid through bilateral and multilateral agencies, NGOs, churches, and private donors (Crook, 2015). After the 2010 earthquake, the aid response from the international community was astounding. The world spent over $\$ 5.2$ billion on the emergency relief alone. Private donations reached $\$ 1.4$ billion in the US (Katz 2013). When time was ripe for planning for the post-earthquake recovery, the world pledged over $\$ 10$ billion with the goal to build a "better, safer, and more prosperous Haiti than before" (Katz 2013). Even with all of this aid, Haiti is considered the most impoverished country in the Western Hemisphere and has the highest rates of maternal mortality in the region, with 359 deaths per every 100,000 live births (WHO, UNICEF, UNFPA, WBG, 2015). Health services within Haiti only reach between $40-60 \%$ of the population (Haiti: Health Action in Crisis). 
A systematic approach to improve health equity within $3 r d$ world communities -evidence from the ..

In Haiti, access to healthcare is contingent upon two factors: distance to facilities and ability to afford care. The main issues relevant to access healthcare in Haiti can be seen based on the geographical location. Administratively, Haiti is divided into ten departments, or secondary administrative divisions of the country. Other than the capital Port-au-Prince where half of the total population lives, Haiti is widely undeveloped with a rural mountainous terrain (World Factbook).

Medical services, private and public, are disproportionately located in Port-au-Prince area (BarnesJosiah et el, 1998). The two national referral maternity hospitals in Port-au-Prince account for $60 \%$ of all hospital deliveries, though obstetric services are available in urban Haiti, the problem with access to healthcare for urban Haitians is the quality of services and ability to pay. High quality private care is only available to those with ample financial resources (Barnes- Josiah et el, 1998).

Public facilities, on the other hand, are characterized by overworked and underpaid staff and inadequate supplies (Barnes- Josiah et el, 1998). While these services are free, the indirect costs associated with meals, drugs, and supplies, can quickly become a burden to the patient's family. Therefore, the majority of families cannot receive the quality care that is needed (Crook, 2015). The primary objective of this paper is to find a systematic approach to ensuring equitable distribution of healthcare services in third world countries, particularly in least developed countries using Haiti an economically impoverished country in the Western Hemisphere as the litmus test.

To establish the proposed hypothesis, the study relied on existing research through an extensive literature review that focused on a comparative and descriptive analysis of an almost non-existing healthcare system in Haiti to that of China's improved and evolving healthcare system. Whilst China is regarded internationally as a developing country despite its remarkable economic achievements within the past three decades, Haiti, also a developing country could be regarded as under-developed compared to China. By conducting an investigation into selected areas within the health sectors in both countries, this paper hypothesized that China's success and feasible improvement within the health sector could be used as template for improvement in the healthcare sector in Haiti and as lessons for other third world countries to emulate.

\section{BACKGROUND AND COUNTRY PROFILE}

The Republic of Haiti is a Caribbean country located in the Western hemisphere. Haiti is located on the Island of Hispaniola in the Greater Antilles archipelago. It shares borders with the Dominican Republic. The country has an area of 10,714 square miles occupied with over 10, million inhabitants (National Census Bureau, 2014). The Haitian population is predominantly female with more than half of the population under 21 years (EMMUS-V, 2012). The majority of Haitians live on less than two dollars per day, making them unable to provide for their basic needs (World Bank, 2016).

The population has limited access to resources and quality healthcare services. In 2014, Haiti ranked 168 out of 187 countries. With a Human Development Index (HDI) of 0.456, Haiti falls lowest on three measures of the human poverty (UNDP, 2014 \& World Bank, 2014) compared to other developing nations in the Caribbean. The United Nations Population Funds (UNPF, 2012) reported the life expectancy in Haiti to be 63 years. Healthcare in Haiti even though free, for children younger than 5 years, is of limited coverage and there are recurring costs for care and shortage of medical supplies.

Haiti - Human development index $(1=$ perfect $/ 0=$ bad $)$

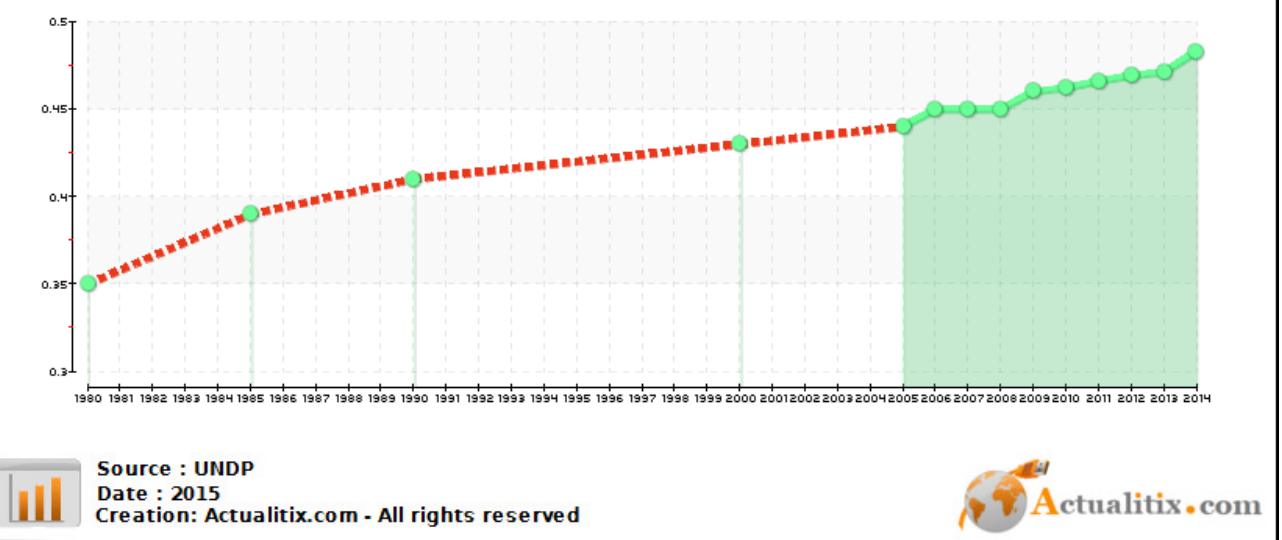

Fig.1. Haiti 2014 Human Development Index- source Actualitix.com 
A systematic approach to improve health equity within 3rd world communities -evidence from the ..

One of the primary reasons healthcare services have been very deficient in Haiti over the past decades is a lack of human resource in the medical field. An analysis on the health system workforce reported 5.9 physician and 6.5 nurses for 10,000 inhabitants, providing only $60 \%$ of the health coverage for the entire country, ("Ministère de la Santé Publique et de la Population).

Provision of health services has been provided on a shoestring around the country, but the recent catastrophic earthquake has hindered tremendous efforts that have been made to improve the health system of Haiti. Health services are mostly centralized in urban areas. With road and transportation infrastructure issues, patients can hardly be transported from their village to a hospital (Germain et al, 2011).

Germain and his colleagues found that based on data collected during their 2009 survey on healthcare services in Haiti, the health system was showing steady improvement in for example maternity services but the unfortunate massive earthquake of magnitude 7.0 on January 12, 2010 devastated Haiti by killing over 230, 000 people and leaving more than 1.5 million homeless. "It has greatly hindered the efforts of the government, private sector and NGOs working in the health sector to decentralize health services and provide improved care to the population", they asserted.

The January 2010 earthquake disrupted national immunization activities that had been planned to address a diphtheria outbreak in various departments, including the Port-au-Prince metropolitan area. Many health facilities participating in the Expanded Program on Immunization (EPI) were destroyed during the earthquake, and others were temporarily unable to function, further weakening EPI capacity to support and supervise vaccination activities at national and departmental levels (Haiti, 2012).

Conditions that heightened the threat of outbreaks of disease were the concentration of large populations in temporary, overcrowded camps and the influx of thousands of expatriates who were involved in earthquake relief activities, including from regions where measles, rubella, and other vaccine-preventable diseases are in circulation. Tetanus vaccination and serum were made available in hospitals that treated the injured. Two rounds of vaccination for measles, rubella, tetanus, pertussis, and diphtheria were organized following the earthquake. Vitamin A supplements and de-worming medication (albendazole) were distributed in targeted areas Ouest and Sud-Est departments and the Port-au-Prince metropolitan area (Haiti, 2012).

Poor access to potable water and proper sanitation remains a major risk to public health in Haiti. Before the January 2010 earthquake, regular access to drinking water was only available to $63 \%$ of the country's population; a mere $10 \%$ to $12 \%$ of the population had access to piped water, but only intermittently. Damage caused by the earthquake disrupted these services in the Port-au-Prince metropolitan area, but no figures are available on the extent of damage (MSPP, 2012). In camps for people displaced by the earthquake, access to drinking water is only available to $40 \%-45 \%$ of the population.

In terms of sanitation, statistics released prior to the earthquake indicate that only $17 \%$ of the population had access to improved sanitation services. Waste disposal facilities in the country are inadequate: household trash, rubble, excreta, and biomedical waste are commonly seen along streets and waterways (MSPP, 2012). "The low income and social development levels, coupled with a lack of sanitation services, contribute to the high incidence of communicable diseases and subsequent economic losses. In health care centers, availability of safe water is a major problem that also poses a potential risk for transmission of waterborne diseases such as cholera. More than $30 \%$ of the health care centers have no access to safe water, and even though $80 \%$ of them have pit latrines, only half of these meet sanitation requirements".

According Germain et al, healthcare access deficiency leads inhabitants to turn towards popular and cultural beliefs, traditional and voodoo healers. Haitian females of childbearing age lack access to evidencebased healthcare which prevents them from having control over their basic health services decisions. "Indeed, about $75 \%$ of the 350000 annual childbirths are home deliveries without any medical assistance. As a consequence, infant and maternal mortality rates are the highest in the western hemisphere". In a 2014 paper published in the International Journal of Environmental Research and Public Health, Zahedi et al found that in Haiti roughly 353 women per 100,000 die of cervical cancer each year, the second highest cancer-related mortality rate among Haitian women (7.1 per 100,000). "It is likely that these estimates are significantly lower than the actual number of cervical cancer cases and deaths in Haiti, since there is a low level of awareness, limited access to screening services and no national cancer registry". To meet the goals set by the Universal Declaration of Human Rights to promote health and ensure adequate access to medical care (UDHR, 1963), health systems need to ensure that health care providers are well-trained and competent (Garcia-Barbero, 1995). Continuing Medical Education (CME) has long been used in high-income countries to facilitate the ongoing acquisition of knowledge and skills by health care professionals with the aim of improving patient care (Shojania et al). Despite the important role CME programs have in maintaining physician accreditation in highincome countries, there currently have been few opportunities for ongoing CME in low-income countries Hudspeth (2015). Regardless of a long tradition of medical education in Haiti, medical education resources remain inadequate to meet the country's needs. Haitian physicians have expressed a lack access to professional development programs and CME activities (Nadas 2015). 
A systematic approach to improve health equity within 3rd world communities -evidence from the ..

Consequently, human resource for health remains one of the areas where little progress has been made in Haiti. The impact of the 2010 earthquake and the cholera epidemic on the health system as a whole further complicated the situation. Haiti has not established an Observatory of Human Resources in Health where reliable figures on the health workforce can be obtained. Since the January 2010 earthquake many private, bilateral, and international partners have increased their involvement in the health sector but the Ministry of Health has had little control over the influx of health workers hired by these different stakeholders (Haiti, 2012).

As the country emerges from the disaster period, there is a need to strengthen the Ministry of Health department which is responsible for human resources development. The health management capacity building project administered by CIDA (Canada) and the Clinton Foundation (U.S.) are contributing to this effort. Of particular concern is how to strike the right balance between administrative/support staff and staff directly providing health services.

For example, between September 2010 and February 2011 a total of 1,159 people was hired by the Ministry of Health to fill 768 administrative/support posts and 391 health care service posts despite the fact that the country was faced with a major cholera epidemic (MSPP, 2012). "Other important challenges include improving the career paths and status of health care providers, instituting a policy for competitive selection of candidates for health posts, and developing a clear policy for remuneration of health care providers. The issue of higher pay and better working conditions offered by international partners based in Haiti needs to be addressed to prevent further losses of qualified personnel by the public sector".

\section{POLITICAL AND ECONOMIC INSTABILITY}

Political violence has occurred regularly throughout Haiti's history, leading to instability. At Independence in 1804, Haiti was at the forefront of history, being the first nation to abolish slavery. Since then, however, with some exceptions such as the 30-year period of autocratic rule under Francois Duvalier (Papa Doc) and his son Jean-Claude Duvalier (Baby Doc) (1957-1986), Haiti has known a succession of short-lived governments. Lacking sufficiently long periods of stability, the country has struggled to develop the institutional mechanisms and policy fundamentals essential to economic development and the rule of law (WBG, 2015). Disenfranchised and without effective channels to voice needs and demands, citizens have taken to the streets in protest, sometimes violently. While violent airing of grievances in Haiti's early history generally took place in the rural areas, contemporary unrest tends to break out in the cities, reflecting the country's demographic evolution and urbanization over the years. Against this backdrop, the post-earthquake period has been comparatively stable.

The structure of the private sector shows signs of high degrees of concentration, hampering the entry of new actors and resulting in high prices for consumers. From the beginning of the twentieth century, autocratic leaders in Haiti have traded political support from the elite for economic advantages to these elite. Though publicly available information on privately held businesses is limited, many of the same families who dominated the Haitian economy during the era of Duvalier in the 1970s and the 1980s seem to remain in control of large segments of the economy today, resulting in high concentration in a number of key industries, distorted competition, and non-transparent business practices in many instances (WBG, 2015).

Several of the most important food products in the Haitian consumption basket are sold in concentrated markets, and a preliminary analysis indicates that the prices of these products are on average about 30 to 60 percent higher in Haiti than in other countries from the region. This translates into limited opportunities for a substantial expansion of the formal private sector across most sectors. Few of Haiti's established private firms have modern capital and governance structures with professional management, limiting their access to long-term financing (WBG, 2015).

\section{THE RESEARCH PROBLEM}

For many developing or third world countries with Haiti not an exception, expenditure on healthcare remains one of the most critical expenses. Concerns about health expenditure growth and its long-term sustainability have stimulated the development of health expenditure forecasting models in many countries, both developed and emerging economies. Whether it is because of concerns surrounding the fiscal sustainability of public expenditures, rising health cost, the productivity of the health sector, financial pressures on patients and families or extending coverage, policy makers are seeking to understand how health expenditure might evolve and to set a course for policy. This remains a bane in the healthcare sector in Haiti.

Additionally, recognition of illness and the potential benefits of treatment are prerequisites for health care demand. Where a large proportion of the population is in poor health, this becomes the norm and illness is not easily recognized. If treatment coverage is low, there is less opportunity to learn of its benefit. The unfortunate outcome can be the continued toleration of illness and disease. In the case of Haiti, the problem described above is historical rooted since the foundation of the Republic of Haiti in 1804. The nation has not been able to fully implement a functioning healthcare policy and system for its citizens. The reason being, it's 
A systematic approach to improve health equity within 3rd world communities -evidence from the ..

failing economy and poor infrastructure which has suffered since independence from France. The colonial powers at that time never imagined African slaves could successfully fight and gain their freedom.

As a result, France together with two other major slave trading nations the United States of America and Canada turned against Haiti using restrictive policies thereby making it extremely difficult for the country to maintain socio-economic stability. Since independence, political upheavals, coup d'état, natural disasters including earthquakes coupled with outbreaks of highly infectious diseases has made the provision of critical and primary healthcare inaccessible to the larger population. This study recognizes these problems as significant and therefore should be tackled not just theoretically but should extend to the implementation of recommended solutions and strategies.

\section{FINDINGS}

Taking into consideration data analyzed in the comparison, namely the comparison of Healthcare in Haiti to Healthcare in China (WHO Statistical Profiles), comparison of Health and Death related disease using data from GHDx and IHME and comparison of Maternal, Newborn and Child Survival statistics by UNICEF (2012 Report) one can safely say that the healthcare sector in China is far more improved and well advanced ahead of most third world countries with the exception of Cuba which has well advanced medical care.

That is to say that the Haitian government and the Ministry of Public Health and Population in Haiti could take a cue from reforms in China to rejuvenate the healthcare sector in the Caribbean country. It could also be argued that improvement in healthcare provision in China came about as a result of the country's economic strides where data from GHDx and IHME indicated that China's 1.4 billion population had a GDP per capita that stood at $\$ 12,702$ with whilst Haiti's 10.7 million population had $\$ 1,384$, a difference of $\$ 11,318$ in per capita income.

China's huge population was also taken into consideration as there were some figures that at times were outrageous compared to Haiti's tiny population. For example, comparing statistics for population aged above 60 years in 2013, China stood at 14\% whilst Haiti stood at 7\%, half of the figure in China- this could also translate that Chinese people have a longer lifespan. This reflected in the comparison of life expectancy where healthy life expectancy for both sexes in Haiti recorded was 7 years lower to China and 11 years lower than overall life expectancy at birth.

Finding on the causes of death in children under-5, immunization and stunted was significant in the comparisons where statistics on immunization among 1 year old where between the years 2010-2015 China recorded 90\%-99\% immunization rate compared to level between $40 \%-90 \%$ for the years under review. This means that China had a high immunization program that was worthy to replicate in Haiti and other third world countries. It proved the equitable distribution of healthcare services despite the size of China's population.

The comparisons revealed that contraceptive prevalence China was higher than in Haiti which is struggling with high records of sexually transmitted disease. With China recording contraceptive use of $85 \%$ and $80 \%$ within country and $\mathrm{WHO}$ region respectively, Haiti recorded $35 \%$ and $74 \%$ within country and $\mathrm{WHO}$ region respectively. The study also found that the top ten causes of death in the two countries was stroke where China recorded 2,331.3 thousand deaths (per 1000) representing 23.7\% in 2012, with Haiti recording 10,700 thousand death (per 1000) representing $12 \%$ in that same year. For lower respiratory infections within the same period China recorded 207.9 (per 1000) representing 2.1\% a fall in infection whilst Haiti recorded 7.7 (per 1000 ) representing $8.6 \%$ without change.

In comparing statistics for death caused by broad groups including HIV, TB, malaria, acute respiratory infections, other infectious diseases, maternal, neonatal nutrition, cardiovascular diseases, diabetes and cancers it was found that Haiti recorded high figures compared to China, taking into consideration population aggregates in both countries.

Between the years 2000 to 2012, deaths for males in China in these six groups (per 1000) were between 4000 - 5000, whilst death recorded in males in Haiti were 30,000 - 50,000. Figures for females in both countries were lower than males. In China figures recorded for females were between 3000-5000, whilst Haiti recorded between 30,000- 45,000. Another significant data set in this group was cardiovascular diseases and diabetes which was high especially in Haiti where death toll recorded for males ranged between 12,000-25,000 and 3000-4200 and for males in China within the period 2000-2012.

Finding on the probability of dying between relevant ages for a person experiencing the 2012 agespecific mortality risk revealed that the probability of dying before age 15 males in China recorded $7 \%$ to $30 \%$ in Haiti, a difference of $23 \%$, whereas figures for females in China were $6 \%$ to $26 \%$ in Haiti, a difference of $20 \%$. For the probability of dying before age 70 males in China recorded $46 \%$ to $71 \%$ in Haiti, whereas females in China $36 \%$ to $65 \%$ in Haiti, a difference of $29 \%$. For the probability of dying between ages 15 and 49 from maternal cause's females in China recorded 1\% compared to $14 \%$ in Haiti. And lastly for the probability of dying between ages 30 and 70 years from 4 major Noncommunicable diseases for both sexes China recorded $19 \%$ compared to $24 \%$ in Haiti, a difference of $5 \%$. The result here was an indication that China's healthcare 
A systematic approach to improve health equity within 3rd world communities -evidence from the ..

services were on track and addressing the problems targeted. The study found that the 2010 earthquake in Haiti had significant impact on health data recorded that year, which presumably could have been different if the natural disaster had not occurred. Comparison from the data analyzed from statistics on 'what causes the most deaths?' from the two countries from the period 2005- 2015 revealed cerebrovascular diseases were the number one causes of death in China within the period under review whilst HIV/AIDS slipped from number one to three in Haiti within the period under review. Significant here in the case of China was the $-14.3 \%$ change in lower respiratory infection and in the case of Haiti $-50.1 \%$ change diarrhea within the period under review. Figure for risk factors that drive the most deaths and disability combined revealed that in China, the most prevalent causes were dietary risks, high systolic blood pressure, and smoke from tobacco and air pollution. In Haiti, the leading risk factors were child and maternal nutrition, unsafe sex, high systolic blood pressure, air pollution and dietary risks.

The comparisons also revealed that there was a high demand for family planning where China reported 97\% in 2006 as against 39\% for Haiti in 2005. For example, for institutional deliveries China recorded $96 \%$ in 2009 compared to $25 \%$ Haiti in 2005. For antenatal care China recorded an average of $90 \%-92 \%$ within the periods 2005-2009 compared to Haiti $71 \%-85 \%$ under the same period. For skilled attendant at delivery China recorded an average of $98 \%-99 \%$ compared to $23 \%-26 \%$ in Haiti.

\section{DISCUSSION}

Even countries with large economies and well-developed healthcare infrastructure remain plagued with inequitable access to healthcare services. The reasons are both economic and related to health service design and delivery. Regardless of how healthcare services are financed, there are three common, inter-related phenomena that exist across continents and are forcing leaders everywhere to grapple with fundamental healthcare system reform.

How a country's leaders and policymakers decide to address them will continue to create some of the most challenging and politically volatile policy questions of the 21 st Century. How leaders of healthcare organizations adapt to these forces will determine their short-term effectiveness as well as the quality of healthcare available to populations across, the globe. The first phenomenon is related to an aging population which is significant in the case of China from the data analyzed. All developed countries have aging populations, whose numbers will only increase in the decades ahead. A high proportion of the elderly suffer from chronic conditions and the high-cost 'diseases of aging.' This demographic profile is a significant contributor to the second phenomenon.

The second phenomenon is identified as the upward-spiraling costs of healthcare delivery. In spite of rigorous efforts to contain costs, current (and future) expenditures are increasing at a faster rate than are the underlying economies that must support the expanding demand for healthcare. The third phenomenon which has persisted since the $20^{\text {th }}$ century is the global Shortage of an adequately trained healthcare workforce. The third equally significant, yet under-appreciated, phenomenon is the ever-increasing global shortage of adequately trained and qualified healthcare personnel. This manpower shortage is pervasive and impacts affordability and accessibility of healthcare throughout the world.

Despite improvements in providing access to health care in developing countries, substantial proportions of their populations have limited access. The poor in these countries suffer from a disproportionate burden of disease yet usually have less access to health care, whether measured by geographic accessibility, availability, financial accessibility, acceptability, or quality of care. However, recent studies show that this outcome is not inevitable (David et al, 2008). Success depends in part on gaining a local understanding of the dimensions and determinants of access to health services, along with determined attempts to improve services for the poor.

There are many innovations in financing, service delivery, and regulation of care that hold promise for improving access for the poor. The same can be said of older strategies. In either case, the challenge remains to find ways to ensure that vulnerable populations have a say in how strategies are developed, implemented, and accounted for and to ensure that information and incentives are aligned in ways that can demonstrate improvements in access by the poor.

Regulatory approaches are often neglected as ways to improve access to health services, but they may also hold potential. It is important to recognize the degree to which poor people in many countries seek health care, purchase drugs, and find health-related information in markets that are mostly unregulated (Bloom et al, 2008). Solutions that work well in a context of strong states and/or civil society regulatory arrangements have different outcomes in other situations. Pritchett and Woolcock argue that this is why many poor countries have come to rely increasingly on a variety of strategies for making programs accountable to communities that may include transfer of resources and responsibilities to small, local organizations. Institutionalized coproduction has been proposed as an emergent model for delivering and regulating services, particularly in areas where governments have not succeeded in ensuring that services are delivered to large segments of society (Pritchett 
A systematic approach to improve health equity within 3rd world communities -evidence from the ..

and Woolcock, 2004). This scenario comprises situations where governments and citizen groups share public services and their regulation. Reforming hospitals is part and parcel of reforming service delivery and adapting PCIC-like models. Hospitals will continue to play an important role, but one that over time is less financially dominant and more focused on providing only the specialized services that only they can offer.

As primary care is strengthened and the PCIC model is put in place, a wide range of care processes will be shifted out of hospitals to ambulatory settings (e.g., certain surgeries and diagnostics, chemotherapy) and primary care facilities. Hospitals will become centers of excellence but with adequate volume to deliver high quality care. They can perform important training and workforce development functions.

They can also focus more on biomedical research and providing clinical support to lower level providers. As described in the chapter, some of these functions are slowly rolling out in China. Across the globe, PCIC initiatives are gaining traction as central parts of health care reform. While they have different names, their core features strengthened primary care, a focus on patient needs, and integration with the rest of the health system are ubiquitous. In the United States, the patient-centered medical home model has become an important form of primary care improvement. Across high-functioning European health systems such as those in the Netherlands, the UK, Australia, Canada and Denmark, PCIC-like reforms are taking shape. And even in middle income countries such as Costa Rica, Brazil, Singapore and Turkey there is a marked orientation toward reshaping service delivery upon the foundation of PCIC. Though expanding rapidly, PCIC-like approaches remain local or regional in most of these countries.

In China, central government has enacted a series of policies and supported investments to promote a delivery system based on PCIC (Guo Ban Fa, 2015: nos. 33, 38, 70; CPC, 2009). From a policy perspective, the "paradigm shift" toward a PCIC-like model is already underway in China. Of particular relevance are recent State Council guidelines outlining the roles and responsibilities of different levels of a tiered delivery system (Gu Ban Fa, 2015: no. 70). These guidelines establish the essential tenets and features of the PCIC delivery model in China and set the stage for the core actions presented in this chapter.

Important attributes include strengthening grassroots providers, promoting first contact at grassroots levels, fostering two-way referrals, defining provider roles while fostering integration of providers across a tiered delivery system; emphasizing special care arrangements to treat and manage chronic diseases, expanding the supply of general practice physicians to staff primary care facilities; and organizing provider networks and advancing the use of eHealth and mHealth innovations. Moreover, the Chinese government has made significant investments since 2009 in building and renovating thousands of village clinics, community health service centers, and township health centers to provide the infrastructure that can better support PCIC.

New primary health care provider training programs have spread across the country and thousands of new workers have been trained to provide frontline primary healthcare to address both quality and human resource gaps. In 2013, the central government invested in a program to improve capacity and service provision of Traditional Chinese Medicine as a way to further augment frontline service delivery capacity.

\section{CONCLUSION}

Haiti is hampered by some of the world's worst health indicators. In order to overcome these challenges and strengthen the country's overall health care network, it is essential that the Government of Haiti improve its capacity to address public health issues (USG, 2014).

Haiti relies heavily on international aid. A 2016 report by the Health Policy Project on the Health Financing Profile of Haiti revealed that in 2012, external sources to Haiti accounted for $64 \%$ of Total Health Expenditure (THE). Additionally, out-of-pocket payments account for fully $30 \%$ of THE, with $3.4 \%$ of households facing catastrophic health expenditures in 2013 (Figure 2). Equitable and accessible care remains a challenge, partly because almost $90 \%$ of the health budget is allocated to paying health personnel, which limits fiscal space to fund other expenses. The health system is focused on delivering curative care in hospitals rather than preventive care (Haiti, 2016).

To overcome these challenges, the government of Haiti has proposed a new health policy, "La Politique National de Santé," with the overall goal of bringing about universal, equitable, and quality healthcare for all in the next 25 years. Health financing goals include establishing a common fund (Fonds National pour la Santé), which would be funded by earmarks from "sin taxes" on products harmful to health (e.g., alcohol, tobacco), along with public funds, and international aid. Other goals are to develop mechanisms to decentralize the budget, increase the GHE to $15 \%$ of THE, and create a performance-based system (Haiti, 2016).

The literature analyzed in this study convincingly demonstrates the existence of an access problem. Effective health care interventions are underutilized in the developing world, and income-related disparities in use are large. Causes of the problem are also identified: insufficient system resources; inappropriate allocation of resources across levels of care, programs, and regions; inadequate quality; insufficient household incomes; lack of access to credit; prohibitive charges (formal and informal); travel costs; cultural barriers to the 
A systematic approach to improve health equity within 3rd world communities -evidence from the ..

acceptability of services; and misperceptions of illness and the effectiveness of care. Solutions, at a very general level, must address one or more of these causes.

The difficulty lies in the design of detailed policy initiatives that tackle root problems within usually severe economic, institutional, and political constraints (O’Donnell, 2007). Solutions to the access problem need to be further developed at a general strategic level, but more crucially at the level of detailed policy measures. The Commission on Macroeconomics and Health, OECD/WHO, and the World Bank has all made important contributions to the development of broad strategies.

The weight of evidence suggests that health disparities can be addressed. Even in some of the poorest countries, carefully designed programs have brought health benefits to the most vulnerable people. Although public health has traditionally focused on improving the health of the majority, policies and programs can be reoriented to better meet the needs of poor and vulnerable groups.

The research available indicates that a comprehensive approach addressing the social and economic causes of health disparities may be the best avenue for closing the rich-poor health gap in less developed countries. The need to improve the health of the poor is urgent, as the growing rich-poor divide in access to information, technology, and high-quality health care threatens to leave the global poor even further behind.

These new types of approaches to financing, provision, and regulation of services represent new ways to focus attention on improving access to the poor in Low and Middle-Income Countries (LMICs). It is not known whether they can work on a large scale or over a long time, but the demands for greater involvement of communities and the poor indicate that the design and responses of these strategies may be different from place to place and over time (David et al, 2008). "As is the case for the "old" innovations, success will probably depend on whether the efforts are made to show that poor and vulnerable populations are actually benefiting". Nowadays, third world countries should look towards China to fix their economic difficulties. China contains a system where basic needs (food, water, shelter, clothing) necessary for survival are affordable to the poorest. Whereas, in third world countries basic needs are commodities. Therefore, without an economic revitalization it will be quite impossible to ever revive third world countries health systems and have sustainable economic growth which is necessary for a country's health system to properly function and improve.

\section{RECOMMENDATIONS}

Poor quality of health services is a major problem in many, but not all, developing countries. Facilities open and close irregularly absenteeism rates of doctors and nurses can be very high, staff can be hostile, even violent to patients' misdiagnosis is not uncommon medicines are all too often unavailable, sometimes due to staff pilfering for use in private practice and there is inappropriate prescribing and treatment. Deficiencies in quality have direct implications for access to effective health care.

Researchers generally agree that effective responses to health disparities can be found in many sectors, including health, education, finance, environment, agriculture, transportation, labor, and other sectors. A range of interventions, if carefully designed, can work toward reducing inequalities in health and health care.

\section{i. Enacting Pro-Growth and Pro-Poor Policies}

The challenges lie in the identification of the poor and the provision of appropriate incentives to providers. "Often, rising incomes means growing inequalities, as the rich benefit more from technological change than the poor. To counter this effect, policies that promote economic growth should be accompanied by social policies in areas such as education, labor, and primary health care, and by special measures to ensure that the benefits of programs flow to the poor" (Margaret Whitehead et al, 2001).

The extension of health insurance cover is a long-term goal. At low levels of development, a more feasible policy is to maintain reliance on out-of-pocket payments but to grant exemptions to groups, principally the poor, for which price is a major deterrent to use. Interventions that generate external benefits, such as immunization against infectious disease, should also be exempted. In principle, this approach allows the public expenditure subsidy to be concentrated on those most in need financially, but also medically to the extent that poverty and ill health coincide, rather than being dissipated across the whole population, or even concentrated on the better off as is indicated by the evidence reviewed in the 2007 paper by Access to Effective Health Care in Developing Countries: Evidence by O’Donnell.

Criteria for exemptions must be decided. In addition to the currently poor, those vulnerable to falling into poverty through ill health may be targeted. For example, exemptions might be offered to the poorest quintile, indigenous people, migrants, adolescents, refugees, and the socially excluded e.g., slum-dwellers (OECD, 2003). Verification of eligibility based on such criteria is a considerable administrative task. 
A systematic approach to improve health equity within 3rd world communities -evidence from the ..

\section{ii. Investing in Education}

Education (especially universal primary education) helps reduce health inequalities because it enables people to obtain safer, better jobs, have better health literacy, take preventive health care measures, avoid riskier health behaviors, and demand more and better-quality health services.

Advanced communication and interactive distance learning tools provide unique opportunities to bring innovative educational resources to medical professionals in low-income or remote locations, thereby expanding global access to high-quality training programs. Besides enabling access to educational materials and instructors, distance learning programs can assist with supporting relationships among medical professionals across distant locations and provide valuable opportunities for capacity building (Battat et al, 2016).

\section{iii. Directing More Health Benefits toward the Poor}

Because the poor tend to use health services less than the rich, public health programs may use "targeting" strategies to direct more benefits toward the poor. These strategies may identify who is poor and therefore eligible for certain benefits or they may direct programs toward certain areas where poorer people live, or address specific health problems that the poor tend to suffer.

Programs using multiple approaches may be most effective (Gwatkin, 2003). In places where governments charge user fees for public health services, the ability to administer waivers or sliding-scale fees is critical to the success of directing benefits toward the poor.

\section{iv. Training of health workers}

In the case of training of health workers, an international collaborative research agenda should be developed and financed in Haiti to generate badly needed information about the cost and effectiveness of different strategies to improve performance, with special emphasis on which strategies are best adapted to different settings and health areas. Such an agenda might have three parts: (1) research on determinants of performance aimed at developing testable theories that explain health-worker practices; (2) rigorous costeffectiveness trials of strategies to achieve and maintain high-quality performance; and (3) work on summarizing study results and developing guidelines for implementing guidelines.

This agenda should have a realistic timeframe: individual studies could take years to complete, and if multiple generations of strategies must be tested, the timeframe should be at least one or two decades. Moreover, this agenda should provide opportunities to train new scientists. It is highly recommended that the proposed agenda be well coordinated and aligned with other initiatives on health systems research so that time and resources are not wasted (Victoria et al, 2004).

\section{v. Promoting Primary and Essential Health Care}

Primary health care (PHC) is the foundation of patient-centered integrated care. Better outcomes at potentially lower costs are produced by systems that prioritize critical primary health care functions of accessibility, comprehensive capacities for most general non-emergent clinical needs, continuity of care and information, continual quality improvement and integration of care (Macincko, 2009; Friedberg, 2010).

No country can provide high quality, effective person-centered integrated care while also keeping costs low without a robust primary health care system. Primary health care is organized around the health needs of individuals and communities, not simply diseases. Patients need to have confidence in and trust that their health needs will be met in a responsive, quality and timely manner in the primary care setting. They also need to be empowered by knowing that that their own health-promoting behaviors will be amplified through interaction with the formal service delivery system.

\section{vi. Increasing the Availability and Quality of Health Services}

A common prescription for health systems is to direct more resources toward primary-level facilities and care, to increase and strengthen these services so that more people in neglected areas can benefit. NGOs and private contractors can greatly improve the reporting of data on expenditures and outcomes. There is an existing platform that encourages such accountability and transparency for all aid players, donor agencies, large foundations, UN agencies, and NGOs. The International Aid Transparency Initiative (IATI) is a multistakeholder initiative that has developed a standard for publishing information about aid spending. Donors, partner countries, and civil society organizations can publically disclose information on volume, aid allocation, and results of development expenditure (Ramachandran \& Walz, 2012).

In modeling its healthcare system following reforms in China, the MSPP in Haiti would need to deepen the reform of the medical and health systems, promote the interaction of medical services, health insurance and pharmaceutical supply, implement the tiered delivery system and establish primary care and modern health care systems that cover both urban rural areas. 
A systematic approach to improve health equity within 3rd world communities -evidence from the ..

Efforts should be made to optimize the layout of medical institutions, improve the medical service system featuring the interaction and complementarily of higher and lower levels of institutions, improve the model of medical service at the grassroots level, develop distance medical service, promote the flow of medical resources to the grassroots level and rural areas, and promote work concerning general practitioners, family doctors, and the medical service capacity of highly needed areas, and electronic medical records.

Efforts should be made to encourage social forces to develop the health service industry, promote the equal treatment of non-profit private hospitals and public hospitals, strengthen supervision and control of medical quality, improve mechanisms for dispute resolution, and build harmonious relations between doctors and patients. In moving forward with the delivery reforms, the MSPP in Haiti should consider maintaining its focus on achieving more health rather than more treatment. This would suggest shifting the focus from rewarding volume and sales to rewarding health outcomes, and achieving more value for the money spent. It would also suggest paying particular attention to providing affordable and equitable health care for all population groups, so that the poor and disadvantaged people do not face the risks of catastrophic medical spending and forego medical care because of unaffordability.

Making the shift from a health care delivery system focused on production of treatments to one focused on value and producing health suggests a strategic agenda that aligns all stakeholders and works toward three goals: (i) attaining better health for the population; (ii) providing better quality and care experience for individuals and families; and (iii) achieving affordable costs.

\section{vii. Redefine the role of facilities, especially hospitals, within a vertically integrated network}

To ensure coordination and continuity, vertical integration requires cooperation among health facilities at different levels of the healthcare system, many of which do not traditionally collaborate. It is therefore necessary to redefine the roles of facilities to function within a robust vertically integrated network, determine what range of services specific health facilities will provide, and decide how higher-level facilities will support lower level facilities through supervision, technical assistance, and partnership. Internationally, the role of hospitals is changing.

They are no longer standalone facilities at the center of the delivery system, the point of entry to care, or "one-stop shops" for all services. Rather, they are becoming part of a network of facilities that includes other providers such as primary care, diagnostic units and social services (Porignon, et al., 2011). They will become centers of excellence concentrating technology and expertise and focusing on providing high complexity care and valuable rescue services for life threatening conditions.

They will also share personnel and provide technical assistance and training to lower levels. Integrating county hospitals, township health centers, community health centers, and village clinics is not a particularly new concept in China but one that continues to be difficult. Often, integration can force numerous health facilities into new roles that may be uncomfortable and foreign to them, but clarifying roles from the outside can provide needed direction and guidance. A prime example of this is Xi, IC. In June 2014, four county hospitals and 19 THCs were contracting with each other for inpatient care.

\section{viii. Establish electronic health records systems (EHR) accessible to providers and patients.}

At the center of an effective eHealth system is the electronic health record which has been shown to improve clinical decision support, registries, team care, care transitions, personal health records, TeleHealth technologies, and measurement (Bates \& Bitton, 2010). When these key factors function smoothly in a healthcare setting; both providers and patients experience a more coordinated care pathway. Providers across different levels are able to communicate in real-time and easily access current and new patients' health information in one place.

In Xi, IC, a new EHR management system was developed that allowed township health centers to monitor clinical services at village clinics, providing critical information about the state of their dual referral system and linked inpatient and outpatient facilities. Physicians at THCs can view the outcome of follow-up appointments and whether or not the referred-to physician adhered to clinical pathways and the individualized care plan developed by the upper-level facility doctor. The EHR system also captured patient referrals.

\section{ix. Embed the "quality culture" in medical organization management philosophy and promote modern managerial techniques.}

High quality health care does not arise from "inspection" alone, and that safety assurance and sustained quality improvement requires a quality culture and continuous attention to quality improvement by managers and staff. Important cultural factors that foster quality improvement include openness toward errors, less hierarchical management, more collaborative teamwork and learning environment, and a focus on continuous system improvement. In contrast, the accountability mechanism centered on individuals and sanction of individual providers for errors by "name and shame" contribute to a culture that averts reporting errors, as well 
A systematic approach to improve health equity within $3 r d$ world communities -evidence from the ..

as a deeply embedded belief that quality of care is the result of being well-trained and trying hard. Sound scientific evidence exists for treating many conditions and can drive care improvement, and in some cases, lower costs. But much of this science is not fully applied in daily clinical practice. Identifying and filling the gap between what is known and what is done requires continuous quality improvement efforts at each health organization.

Health organizations can benefit from using modern managerial approaches to improve quality through changing health worker behaviors and optimizing clinical care system (Langley, Nolan and Nolan, 2009; Deming, 2000). For example, Continuous Quality Improvement (CQI) and Total Quality Management (TQM) approaches emphasize a continuous effort by all members of the organization to meet the needs and expectations of clients.

Managers and clinicians work together to identify undesirable variations in process of care and try to eliminate them. Six Sigma targets reducing error rates to six standard deviations from the process mean to ensure standardized service, where appropriate. Plan-Do-Study-Act (PDSA) cycle is a mechanism in which clinical teams learn how to apply key change ideas to their organizations in a series of testing "cycles", using specific and measurable aims that are tracked over time.

These and other management approaches can be combined and applied with flexibility, but the intention is to cultivate a sense of continuous attention to the quality improvement in management practice through such activities. Some of them are already under implementation in some large Chinese hospitals, for example, Anzhen Hospital applied the PDSA to hospital strategic management (Nie et al, 2014), Peking University People's Hospital used TQI with PDSA to improve the efficiency of specialist clinic registration (Chen et al, 2014). Lessons from these experiences should be examined and similar initiatives expanded throughout Haiti.

\section{x. Use EHR to support quality improvements}

Electronic health record (EHR) systems provide a digital version of all of a patient's medical and clinical records and a comprehensive patient history. EHRs, correctly designed and carefully implemented, can help with data capture and sharing for measurement and feedback on quality of care, real time clinical decision support, and improving coordination of care and patient-provider interaction. Currently much health-related information in China is based on the official and routine reporting system without independent verification.

Over the past decade, China invested in upgrading the health information infrastructure, introducing computers and electronic health record systems in many facilities including village clinics. This provided a good foundation for improving the national health information system by adding rich clinical data to the existing body of data derived from household surveys, surveillance of communicable diseases, and periodic disease-specific prevalence surveys.

Some localities have used HER systems to support clinical processes. Feixi, SCPHC used medical information technology system to limit doctor's prescriptions to recommended drugs for specific conditions, and to prompt physicians to follow clinical pathways. A similar system was implemented in Xi County, Henan province. Advanced applications using computer algorithms and clinical data mining are used to support realtime automatic hospital-wide surveillance of nosocomial infections and outbreaks in the Chinese PLA General Hospital (Du et al, 2014). China may like to rigorously evaluate the impact of these changes to improve processes and administration of medication.

\section{ACKNOWLEDGEMENTS}

I would like to take this opportunity to thank all those people who have made the completion of this thesis possible. My thanks of course go to my classmates (Leidy, Ashleigh, Wang Ting and Lee) who gave their valuable time to meticulously go through this study and for their invaluable advice. My special thanks go to my supervisor, Zhang Zhiguo who had the patience to teach and work with me and took the time to go through my papers diligently. My appreciation also goes to Luanettee' Colebrooke and Tanza who gave me the motivation that I needed to complete this paper. Most of all, I thank my God, Jah and my cousin Patrick Fleurimond from back home who always checked up on me and gave me the added confidence I needed to complete this task.

\section{REFERENCES}

[1]. Barnes-Josiah, Debora, Cynthia Myntti, and Antoine Augustin (1998) "The "Three Delays" as a Framework for Examining Maternal Mortality in Haiti."Social Science \& Medicine

[2]. Bates J FH, Schrewe B, Jamieson J, Ellaway R. (2011) - Distributed Education and Distance Learning in Postgraduate Medical Education, Members of the FMEC PG consortium.

[3]. Bates, D.W., and A. Bitton. 2010. "The Future of Health Information Technology in the Patientcentered Medical Home". Health Affairs (Millwood) 29 (4):614-21.

[4]. Bloom, G. et al. (2008) Markets, information asymmetry and health care: towards new social contracts 
A systematic approach to improve health equity within 3rd world communities -evidence from the ..

[5]. Crook, Allison M (2015) The Effect Of International Aid And Development On Maternal Health In Haiti

[6]. China Joint Study Partnership (CJSP, 2016) Deepening Health Reform in China -

[7]. Building High-Quality And Value-Based Service Delivery Policy Summary-: World Bank Group, World Health Organization, Ministry of Finance, National Health and Family Planning Commission, Ministry of Human Resources and Social Security

[8]. China CDC. China National Plan for NCD Prevention and Treatment (2012-2015)

[9]. (http://www.chinacdc.cn/en/ne/201207/t20120725_64430.html accessed on 29 February 2016)

[10]. Chen Gao, Fei Xu, Gordon G. Liu. 2014. "Payment Reform and Changes in Health Care in China." Social Science \& Medicine (111):10e16.

[11]. CIA World Factbook 2008, U.S. Dept. of State Country Background Notes

[12]. David H. Peters, Anu Garg, A Gerry Bloom, Damian G. Walker, William R. Brieger, And M. Hafizur Rahmana (2008) Poverty and Access to Health Care in Developing Countries Available from Research Gate.

[13]. Deming, William Edwards. 2000. The New Economics: For Industry, Government, Education. MIT Press. Cambridge, MA.

[14]. Du, Mingmei, et al. 2014. "Real-time Automatic Hospital-wide Surveillance of Nosocomial Infections and Outbreaks in a Large Chinese Tertiary Hospital.” BMC Medical Informatics and Decision-making 14.1:9

[15]. EMMUS-V, 2012- Haiti Mortality, Morbidity, and Service Utilization Survey: Key Findings. Calverton, Maryland, USA: MSPP, IHE, and ICF International.

[16]. Friedberg, M.W., P.S. Hussey, and E.C. Schneider. 2010. "Primary Care: A Critical Review of the Evidence on Quality and Costs of Health care." Health Affairs (Millwood) 29 (5):766-72. doi: 10.1377/hlthaff.2010.0025

[17]. Felker-Kantor, Erica Ann (2011) Perceptions Of Maternal Health Care Among Haitian Women In The Dominican Republic: Do Race And Ethnicity Matter?

[18]. Guo Ban Fa. 2015. No. 38., State Council General Office, Guidance of the General Office of the State Council on Overall Pilot Reform of Urban Public Hospitals. National Health and Family Planning Commission of the PRC 2015-05-17, Guo Ban Fa. 2015. No. 33, , State Council General Office, Opinions of the State Council on Comprehensively Scaling-Up Reform of County-level Public Hospitals. State Council

[19]. Gwatkin, Davidson, (2003) "The Current State of Knowledge About Targeting Health Programs to Reach the Poor Germain N, Thibaud Monteriro, Evans Emmanuel, E Lamagna (2011) Post-Earthquake health challenges in Haiti: Emergency plan dealing with maternity care assistance. Available from Research Gate

[20]. Garcia-Barbero M (1995). Medical education in the light of the World Health Health for All strategy and the European Union. Med Educ.

[21]. Guo Ban Fa 2015c No. 70, State Council General Office, Guidance of the General Office of the State Council on Promoting Multi-level Diagnosis and Treatment System. 2015-09-11, Haiti (2012) Health in the Americas- Couintry Volume

[22]. Haiti, Ministe`re de la Sante' Publique et de la Population. E'valuation du de'pistage de la tuberculose en 2010. Port-au-Prince: MSPP; 2011.

[23]. Health Financing Profile Haiti May 2016

[24]. Hudspeth J, Curry CL, Sacks Z, Surena C. Continuing professional development in Low- resource settings: Haiti as example. Annals of global health. 2015;81(2):255-9

[25]. Katz, Jonathan (2013) The Big Truck That Went By: How the World Came to save Haiti and Left Behind a Disaster. New York: Palgrave Macmillan,

[26]. Langley, Gerald J., et al. 2009. The improvement guide: a practical approach to enhancing organizational performance. John Wiley \& Sons, New Jersey (USA).

[27]. Macinko, J. B. Starfield, and T. Erinosho. 2009. "The Impact of Primary Healthcare on Population Health in Low - and middle-income Countries." Journal Ambul Care Manage 32(2):150-71. doi: 10.1097/ JAC.0b013e3181994221.

[28]. Margaret Whitehead et al., "Developing the Policy Response to Inequities in Health: A Global Perspective," in Challenging Inequities in Health: From Ethics to Action, ed. Timothy Evans et al. (New York: Oxford University Press, 2001)

[29]. Ministère de la Sante Publique et de la Population (2009). Protocole de prise en charge de la malnutrition aigue globale en Haïti

[30]. Nadas M, Bedenbaugh R, Morse M, McMahon GT, Curry CL. A needs and resource assessment of continuing medical education in Haiti. Annals of global health. 2015;81(2):248-54.

[31]. Nie, Xiaomin, Yongxiang Wei, and Xiaoyan Cui. 2014. "Implementation of Hospital 
A systematic approach to improve health equity within 3rd world communities -evidence from the ..

[32]. Strategic Management under Pdca Cycle." Chinese Hospital Management 34 (3).

[33]. O, O’ Donnell, (2007) Access to health care in developing countries: breaking down

[34]. demand side barriers- Department of Balkan, Slavic and Oriental Studies, University of Macedonia, Thessaloniki, Greece

[35]. Organization for Economic Cooperation and Development/World Health Organization-

[36]. DAC guidelines and reference series - poverty and health. Paris: Organization for Economic Cooperation and Development/World Health Organization; 2003.

[37]. Office for the Coordination of Humanitarian Affairs (2010).Haiti earthquake. Situation report No.34;

[38]. Pan American Health Organization/World Health Organization (2006). The Challenge of Haiti.Health: A Right for All. Washington, DC: PAHO Puentes-Markides, Cristina. 1992. "Women and access to health care." Social Science Medicine 35(4): 619-626.

[39]. Pritchett, L. \& M. Woolcock (2004) Solutions when the solution is the problem: arraying the disarray in development. World Dev. 2: 191-212

[40]. Population Reference Bureau (2004) Improving the Health of the World's Poorest People

[41]. Porignon, Dennis, et al. 2011. "The Role of Hospitals within the Framework of the Renewed Primary Health Care (PHC) strategy." World Hospital Health Service 47 (3):6-9.

[42]. Remillard BD, Buteau JH, Cleophat P. Kidney (2015) care in Haiti-the role of partnerships. Nature reviews Nephrology

[43]. Shojania KG, Silver I, Levinson W. Continuing medical education and quality

[44]. Improvement: a match made in heaven? Ann Intern Med. 2012;156(4):305-8

[45]. The Universal Declaration of Human Rights J Health Phys Ed Recreation 1968;39(3):37-38.

[46]. The World Factbook (2013) Central Intelligence Agency, Washington, DC, USA: Directorate of Intelligence;

[47]. United Nations, Population Division (2005), World population prospects: The 2004 revision. New York.

[48]. Victoria CG, Hanson K, Bryce J, Vaughan JP (2004) Achieving universal coverage with health interventions. Lancet ; 364: 1541-48..

[49]. WHO China statistical profile (http://www.who.int/gho/countries/chn.pdf?ua=1 accessed on 29 February 2016).

[50]. WHO, The World Health Report 2000: 14-16

[51]. WHO, UNICEF, UNFPA, World Bank Group, and United Nations Population Division- (2015) Maternal Mortality Estimation Inter-Agency Group- HAITI

[52]. World Health Organization- World Health Statistics 2016: Monitoring Health for the SDGs Geneva World Health Organization 2016.

[53]. World Health Organization- Health Inequality Monitoring eLearning Module Geneva: World Health Organization, 2015

[54]. World Bank (2014) Reflections for evidence-based policy making Washington, DC: World Bank Group.

[55]. World Bank Group (2015) Haiti: Towards A New Narrative Systematic Country Diagnostic

[56]. WHO. 2014. "Noncommunicable Diseases (NCD) Country Profiles, China 